\title{
Comparing the Effects of Facility-Specific Guideline and Nudge-Based Antimicrobial Stewardship at Pediatric Primary Emergency Medical Centers
}

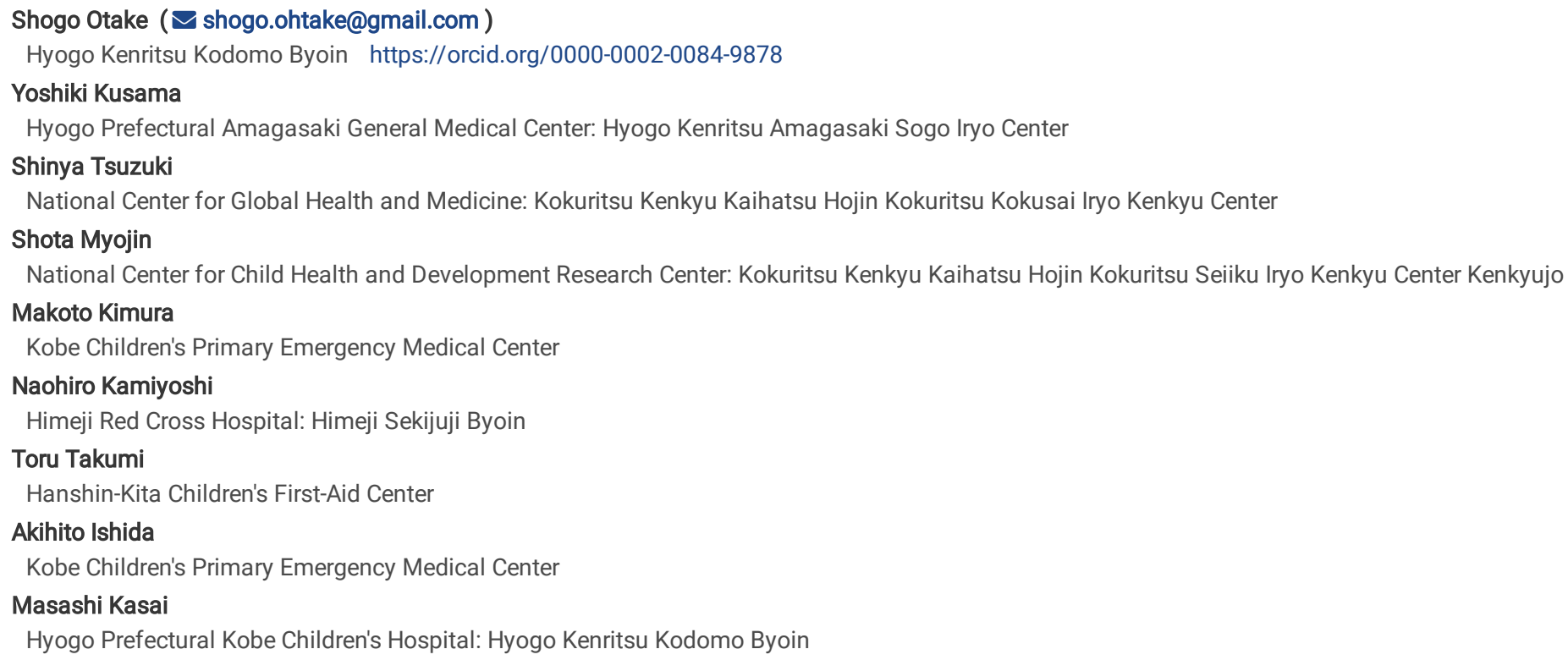




\section{Abstract}

Purpose: Antimicrobial prescription rates tend to be high in outpatient settings. Primary emergency medical centers (PECs) in Japan encounter difficulties in implementing antimicrobial stewardship programs (ASPS). While a nudge-based ASP significantly reduces inappropriate prescription of oral thirdgeneration cephalosporins (3GCs), publishing monthly newsletters requires considerable effort. Therefore, developing more preferable ASP models in PECs is essential.

Methods: We conducted a multi-center, quasi-experimental study. The Himeji Primary Emergency Medical Center for Nights and Holidays (Site A) introduced the facility-specific guideline referring to national guidelines. The Kobe Children's Primary Emergency Medical Center (Site B) provided the results of the monitoring for antibiotics prescription as a monthly newsletter. The Hanshin-Kita Children's First-Aid Center (Site C) did not perform the specific ASP. Prescription rates for 3GCs were categorized into pre- and post-intervention and compared using Poisson regression analysis. The difference-in-difference method was used to assess the effect of these interventions.

Results: The numbers of patients pre- and post- intervention were 177,126 and 91,251, respectively. The 3GCs prescription rate at Site A, Site B, and Site C decreased from $6.7 \%, 4.2 \%$, and $6.1 \%$ in 2016 to $2.3 \%, 1.0 \%$, and $2.0 \%$ in 2019 , respectively. Site B had a greater reduction than Site A and Site C (odds ratio [OR] 0.81 [95\% confidence interval $(\mathrm{Cl}) 0.70-0.93]$; $\mathrm{P}<0.001, \mathrm{OR} 0.76,[95 \% \mathrm{Cl} 0.66-0.87$ ]; $\mathrm{P}=0.004)$. There was no significant difference between Site $\mathrm{A}$ and Site C (OR 0.94 [95\% Cl 0.83-1.06]; $P=0.33)$.

Conclusions: Facility-specific guideline was less effective than nudge-based ASP for decreasing oral third-generation cephalosporins prescription in PECs.

\section{What Is Known}

Outpatient settings such as urgent care centers and primary emergency care centers tend to have high prescription rates of unnecessary antibiotics; therefore, various antimicrobial stewardship programs have been implemented.

\section{"What is New"}

To promote the reduction in prescription of oral third-generation cephalosporins at pediatric primary emergency medical centers in Japan, the introduction of facility-specific guideline was simpler, but less effective than nudge-based antimicrobial stewardship programs publishing monthly newsletters.

\section{Introduction}

Antimicrobial resistance (AMR) is a global problem; the inappropriate use of antibiotics in medical facilities affects the emergence and spread of antimicrobial-resistant bacteria [1]. Moreover, inappropriate antibiotic prescription is associated with adverse consequences, such as increased cases of Clostridioides difficile infection [2, 3]. In the United States, antibiotics are majorly prescribed in the outpatient setting [2], and studies have reported inappropriate antimicrobial use in various outpatient settings (e.g., retail clinics, urgent care clinics, and emergency departments) [4-8]. In these outpatient settings, various antimicrobial stewardship programs (ASPs), such as provider feedback, patient education, communication skills training, and clinical decision support, have been implemented to prevent the rapid spread of antimicrobial-resistant bacteria [9].

In Japan, a study detected that the proportion of oral antibiotics was $92.6 \%$ of total antimicrobials used [10]. An additional notable feature is the high rate of prescription of oral third-generation cephalosporins (3GCs, 35.6\%) and macrolides (37.6\%) for children [11], the majority of which are prescribed for nonbacterial respiratory tract infections [12]. Thus, the low prescription of amoxicillin compared to that in other developed countries is also a major concern [13]. Japanese emergency medical services are categorized into primary, secondary, and tertiary care. Generally, small private clinics provide primary care during hours, and primary emergency care centers (PECs) provide primary care after hours [14]. Since many physicians, including academic researchers and university staff, work as part-time employees, it is difficult to standardize prescribing behavior. Furthermore, due to many patients, we struggle to implement ASPs in PECs compared to in the inpatient setting [14]. We conducted a nudge-based ASP (monitoring of institutional antimicrobial use trends and monthly newsletter reporting of antimicrobial prescription status). We found that our nudge-based ASP significantly reduced the rate of antimicrobial prescribing and inappropriate prescription of oral 3GCs in a pediatric PEC [14]. However, while this strategy was simple and economical, it required considerable effort to monitor antimicrobial prescribing and publish a monthly newsletter. In contrast, facility-specific guideline development does not require frequent repeated effort once published. This study aimed to examine the effect of facility-specific guideline by comparing them with the effect of nudge-based ASP in decreasing $3 \mathrm{GC}$ prescription and to evaluate which is the more preferable method as an ASP in Japanese pediatric PECs.

\section{Methods}

\section{Study design}

We conducted a multi-center, quasi-experimental study using electronic medical record databases from Himeji Primary Emergency Medical Center for Nights and Holidays (Site A), Kobe Children's Primary Emergency Medical Center (Site B), and Hanshin-Kita Children's First-Aid Center (Site C). The period from April 2016 to September 2018 was designated the "pre-intervention" period, and the period from October 2018 to December 2019 was designated the "postintervention" period. No specific ASPs had been conducted at these facilities. We obtained opt-out consent from the patients' parents, and this study was approved by the institutional ethics committees of Kobe Children's Hospital (Approval Number 2020-61), Japanese Red Cross Society Himeji Hospital (Approval Number 2020-39), and Kobe Children's Primary Emergency Medical Center (Approval Number 1). 


\section{Patients and Setting}

Hyogo prefecture is one of the most populous regions in Japan, covering an area of $8,400 \mathrm{~km}^{2}$. The prefecture's population in 2019 was approximately 5.5 million. Himeji city, Kobe city, and Hanshin-Kita area are all included in Hyogo prefecture with areas of $534 \mathrm{~km}^{2}, 554 \mathrm{~km}^{2}$, and $481 \mathrm{~km}{ }^{2}$, respectively. These cities' population in 2019 were 540,000 (including 77,000 children aged 15 years or younger), 1.5 million (including 0.2 million children aged 15 years or younger), and 720,000 (including 0.1 million children aged 15 years or younger), respectively. Sites $A, B$, and $C$ are the regional pediatric $P E C$ s providing after-hour care on weekdays, weekends, and holidays for patients aged 15 years or younger. These centers treat approximately $20,000,30,000$, and 25,000 children per year and accept patients with various medical conditions (including patients arriving by ambulance), except for those requiring surgical interventions and those with severe burns. In these centers, blood tests (complete blood counts and C-reactive protein levels), urinalysis, rapid tests for respiratory diseases, and diagnostic imaging are available. More than 50 physicians are employed as part-time employees in each facility. Each of these part-time employees usually works in their clinic or hospital during the day. Because of the variety of specialties, they do not necessarily have education in primary care. In each PEC, the number of prescription days is limited to 1 to 2 days to encourage follow-up with the patient's regular clinic.

\section{Intervention}

In October 2018, Sites A and B initiated monitoring all antimicrobial prescribing trends at their facilities (particularly including 3GCs and penicillin). In addition, we performed specific ASPs at each of the facilities as described below.

\section{Himeji Primary Emergency Medical Center for Nights and Holidays (Site A)}

We published a facility-specific guideline for children in October 2018, referring to national guidelines: "Manual of Antimicrobial Stewardship. The 1st Edition [15]". The facility-specific guideline recommended the choice (except 3GCs), dosage, and duration of antibiotics for each pediatric infection. Similarly, this guideline stated that antibiotics were unnecessary for common cold, upper respiratory tract infection, bronchitis, bronchiolitis, and gastroenteritis because they were mostly caused by viruses, and that the watch-and-see strategy can be adopted for mild acute otitis media without prescribing antibiotics: this was posted in the consultation room so that all physicians could check them at any time. We collected prescription data once every six months and shared the information of these data in regular meetings twice a year. Since this direct presentation was provided only to some physicians attending the meeting, the main intervention at Site A was the publish of facility-specific guideline.

\section{Kobe Children's Primary Emergency Medical Center (Site B) [14]}

We investigated all antimicrobial prescribing trends and the appropriateness of prescribing 3GCs every month. The results of the monitoring and investigation were provided as a monthly newsletter that summarized recent antimicrobial prescribing patterns and the facility's prescribing targets. Similarly, the newsletters provided recommendations for specific infections and introduced national guidelines. They were posted in the consultation rooms and staff lounges so that physicians viewed it at any time.

\section{Hanshin-Kita Children's First-Aid Center (Site C)}

This facility was a negative control where we did not perform the specific ASP during the period. We retrospectively surveyed the facility's antimicrobial prescribing status in December 2019.

\section{Data collection}

Data were collected using a search tool for electronic medical records at each pediatric PEC. The collected data included the number of patients, patient age, diagnoses, the total number of antimicrobial prescriptions, and the number of specific antimicrobial prescriptions (3GCs and amoxicillin). The patient diagnoses were based on medical receipt data.

\section{Endpoint and Statistical Analysis}

The primary outcome was the trend in the $3 \mathrm{GC}$ prescription rate. The secondary outcomes were the trend in the amoxicillin prescription rate and all antibiotic prescription rate. The antimicrobial prescription rate (\%) was defined as "the number of specific antimicrobial prescriptions/number of patients $\times 100$.

Patient age and diagnosis at each facility were compared pre- and post-intervention. Age was categorized into four categories ( $<1,1-5,6-10$, and $11-15$ years), and the diagnosis was classified into 12 categories (upper respiratory tract infections, pharyngitis/tonsillitis, bronchitis, gastroenteritis, sinusitis, streptococcal pharyngitis, pneumonia, acute otitis media, urinary tract infections, skin and soft tissue infections, and others). "Others" mainly included noninfectious diseases, such as allergic urticaria, Kawasaki disease, constipation, and foreign bodies.

Monthly obtained data were divided into pre- and post-intervention and compared using Poisson regression analysis for the primary and secondary outcomes at three centers. The difference-in-difference method was used to assess the effect of the intervention, the duration, and the difference in facilities on the outcomes. All statistical analyses were conducted using R version 4.0.5 (R Core Team, 2019, Vienna, Austria), and Bonferroni correction for multiple comparisons was applied for $P$ values. Two-tailed $P$ values below .0167 were considered statistically significant.

\section{Results}




\section{Study Population}

Table 1 summarizes the patient characteristics. The total number of patients was 268,377 from April 2016 to December 2019 . Sites A, B, and C treated $47,186,68,910$, and 61,030 patients during the pre-intervention period, respectively. These centers treated $23,304,35,546$, and 32,401 patients, during the post-intervention period, respectively. Patients aged 1-5 years accounted for the majority of visits in all centers during both periods, followed by patients aged 6-10 years. Across all centers, the proportion of diagnoses did not change significantly between pre- and post-intervention.

Table 1

Basic characteristics of patients

\begin{tabular}{|c|c|c|c|c|c|c|c|c|c|c|c|c|c|}
\hline & & \multicolumn{4}{|l|}{ Site A } & \multicolumn{4}{|l|}{ Site B } & \multicolumn{4}{|l|}{ Site C } \\
\hline & & \multicolumn{2}{|c|}{$\begin{array}{l}\text { Pre- } \\
\text { intervention } \\
\text { period }\end{array}$} & \multicolumn{2}{|c|}{$\begin{array}{l}\text { Post- } \\
\text { intervention } \\
\text { period }\end{array}$} & \multicolumn{2}{|c|}{$\begin{array}{l}\text { Pre- } \\
\text { intervention } \\
\text { period }\end{array}$} & \multicolumn{2}{|c|}{$\begin{array}{l}\text { Post- } \\
\text { intervention } \\
\text { period }\end{array}$} & \multicolumn{2}{|c|}{$\begin{array}{l}\text { Pre- } \\
\text { intervention } \\
\text { period }\end{array}$} & \multicolumn{2}{|c|}{$\begin{array}{l}\text { Post- } \\
\text { intervention } \\
\text { period }\end{array}$} \\
\hline & & \multicolumn{2}{|c|}{$\begin{array}{l}\text { (Apr 2016-Sep } \\
\text { 2018) }\end{array}$} & \multicolumn{2}{|c|}{$\begin{array}{l}\text { (Oct 2018-Dec } \\
2019)\end{array}$} & \multicolumn{2}{|c|}{$\begin{array}{l}\text { (Apr 2016-Sep } \\
\text { 2018) }\end{array}$} & \multicolumn{2}{|c|}{$\begin{array}{l}\text { (Oct 2018-Dec } \\
\text { 2019) }\end{array}$} & \multicolumn{2}{|c|}{$\begin{array}{l}\text { (Apr 2016-Sep } \\
\text { 2018) }\end{array}$} & \multicolumn{2}{|c|}{$\begin{array}{l}\text { (Oct 2018-Dec } \\
\text { 2019) }\end{array}$} \\
\hline & & \multicolumn{2}{|c|}{$N=47,186$} & \multicolumn{2}{|c|}{$N=23,304$} & \multicolumn{2}{|c|}{$N=68,910$} & \multicolumn{2}{|c|}{$N=35,546$} & \multicolumn{2}{|c|}{$N=61,030$} & \multicolumn{2}{|c|}{$N=32,401$} \\
\hline & & \multicolumn{2}{|c|}{ Patients, n (\%) } & \multicolumn{2}{|c|}{ Patients, n (\%) } & \multicolumn{2}{|c|}{ Patients, n (\%) } & \multicolumn{2}{|c|}{ Patients, n (\%) } & \multicolumn{2}{|c|}{ Patients, n (\%) } & \multicolumn{2}{|c|}{ Patients, n (\%) } \\
\hline \multirow{4}{*}{$\begin{array}{l}\text { Age } \\
\text { categories }\end{array}$} & $<1$ year & 5,554 & 11.8 & 2,521 & 10.8 & 9,110 & 13.2 & 4,429 & 12.5 & 6,424 & 10.5 & 3,000 & 9.3 \\
\hline & $1-5$ years & 25,991 & 55.1 & 12,445 & 53.4 & 39,059 & 56.7 & 19,406 & 54.6 & 33,211 & 54.4 & 17,201 & 53.1 \\
\hline & $6-10$ years & 9,981 & 21.2 & 5,468 & 23.5 & 14,708 & 21.3 & 8,235 & 23.2 & 15,110 & 24.8 & 8,678 & 26.8 \\
\hline & $11-15$ years & 5,660 & 12.0 & 2,870 & 12.3 & 6,033 & 8.8 & 3,476 & 9.8 & 6,285 & 10.3 & 3,522 & 10.9 \\
\hline \multirow[t]{11}{*}{ Diagnosis } & URI & 14,237 & 30.2 & 6,509 & 27.9 & 18,737 & 27.2 & 9,855 & 27.7 & 14,766 & 24.2 & 7,600 & 23.5 \\
\hline & Pharyngitis/Tonsillitis & 4,952 & 10.5 & 2,797 & 12.0 & 6,944 & 10.1 & 2,750 & 7.7 & 6,418 & 10.5 & 2,928 & 9.0 \\
\hline & Bronchitis & 5,971 & 12.7 & 2,544 & 10.9 & 6,007 & 8.7 & 3,017 & 8.5 & 5,151 & 8.4 & 128 & 0.4 \\
\hline & Gastroenteritis & 8,619 & 18.3 & 3,947 & 16.9 & 10,542 & 15.3 & 5,276 & 14.8 & 9,563 & 15.7 & 4,839 & 14.9 \\
\hline & Sinusitis & 80 & 0.2 & 52 & 0.2 & 37 & 0.1 & 17 & 0.0 & $\begin{array}{l}\text { No } \\
\text { data }\end{array}$ & & $\begin{array}{l}\text { No } \\
\text { data }\end{array}$ & \\
\hline & $\begin{array}{l}\text { Streptococcal } \\
\text { pharyngitis }\end{array}$ & 314 & 0.7 & 194 & 0.8 & 559 & 0.8 & 221 & 0.6 & 799 & 1.3 & 402 & 1.2 \\
\hline & Pneumonia & 164 & 0.3 & 66 & 0.3 & 368 & 0.5 & 124 & 0.3 & 347 & 0.6 & 124 & 0.4 \\
\hline & AOM & 812 & 1.7 & 446 & 1.9 & 1,156 & 1.7 & 574 & 1.6 & 707 & 1.2 & 356 & 1.1 \\
\hline & UTI & 289 & 0.6 & 97 & 0.4 & 437 & 0.6 & 188 & 0.5 & 345 & 0.6 & 156 & 0.5 \\
\hline & SSTI & 213 & 0.5 & 103 & 0.4 & 379 & 0.5 & 172 & 0.5 & 266 & 0.4 & 120 & 0.4 \\
\hline & Others ${ }^{*}$ & 11,535 & 24.4 & 6,549 & 28.1 & 23,744 & 34.5 & 13,352 & 37.6 & 22,668 & 37.1 & 14,588 & 45.0 \\
\hline \multicolumn{14}{|c|}{$\begin{array}{l}\text { Site A, Himeji Primary Emergency Medical Center for Nights and Holidays; Site B, Kobe Children's Primary Emergency Medical Center; Site C, Hanshin- } \\
\text { Kita Children's First-Aid Center; AOM, acute otitis media; SSTI, skin and soft tissue infection; URI, upper respiratory infection; UTI, urinary tract infection }\end{array}$} \\
\hline
\end{tabular}

\section{Primary Outcome}

Figure 1 shows the monthly trends in the $3 \mathrm{GC}$ prescription rate. The rates at Sites $\mathrm{A}, \mathrm{B}$, and $\mathrm{C}$ decreased from $6.7 \%, 4.2 \%$, and $6.1 \%$ in 2016 to $2.3 \%, 1.0 \%$, and $2.0 \%$ in 2019 , respectively. Site B, which conducted a poster nudge-based ASP, showed a significantly greater reduction than Site A, which had a facilityspecific clinical guideline ASP (odds ratio [OR] 0.81 [95\% confidence interval (CI) 0.70-0.93]; $\mathrm{P}<0.001$ ). There was no significant difference between Site A and Site C (negative control) (OR 0.94 [95\% Cl 0.83-1.06]; P = 0.33). Additionally, Site B had a significantly greater reduction than Site $\mathrm{C}(\mathrm{OR} 0.76$ [95\%Cl $0.66-0.87$ ]; $P=0.004)$ (Table 2). 
Third-generation cephalosporins prescription rate

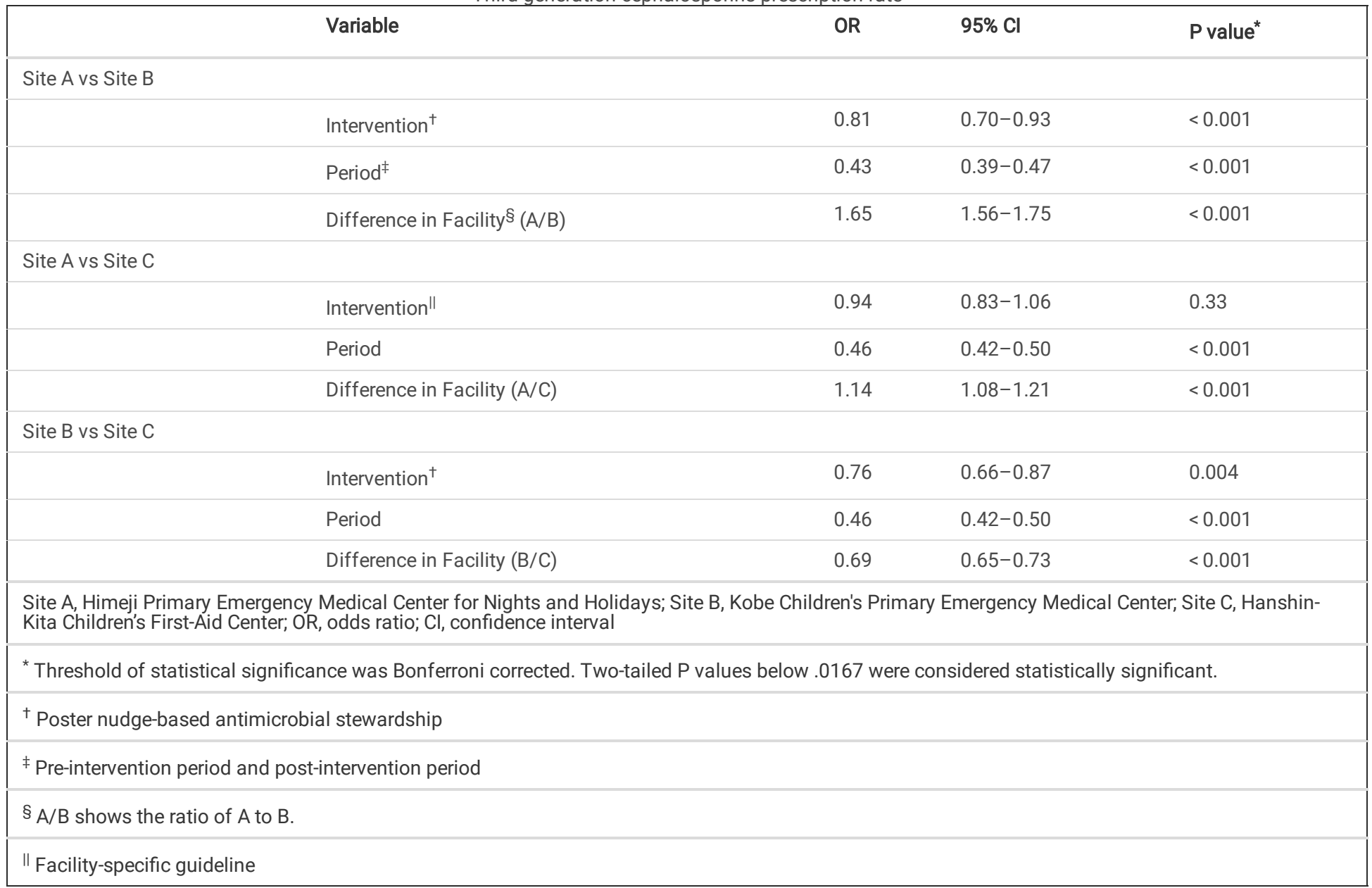

\section{Secondary Outcome}

Figure 2 shows the monthly trends in the amoxicillin prescription rate. The rates at Sites A, B, and C increased from $1.6 \%, 2.2 \%$, and $1.3 \%$ in 2016 to $2.0 \%$, $2.6 \%$, and $1.9 \%$ in 2019 , respectively. There was no significant difference due to interventions among any of the centers: Site $A$ and Site B (OR 0.94 [ $95 \% \mathrm{Cl}$ 0.82-1.08]; $P=0.39)$, Site A and Site C (OR 1.07 [95\%Cl 0.92-1.25]; P=0.36), Site B and Site C (OR 1.01 [95\%Cl 0.89-1.15]; P=0.90) (Table 3). 


\begin{tabular}{|c|c|c|c|c|}
\hline & Variable & OR & $95 \% \mathrm{Cl}$ & P value ${ }^{*}$ \\
\hline \multicolumn{5}{|l|}{ Site A vs Site B } \\
\hline & Intervention $^{\dagger}$ & 0.94 & $0.82-1.08$ & 0.39 \\
\hline & Period ${ }^{\ddagger}$ & 1.23 & $1.10-1.38$ & $<0.001$ \\
\hline & Difference in Facility§ (A/B) & 0.75 & $0.68-0.81$ & $<0.001$ \\
\hline \multicolumn{5}{|l|}{ Site A vs Site C } \\
\hline & Intervention" & 1.07 & $0.92-1.25$ & 0.36 \\
\hline & Period & 1.15 & $1.04-1.27$ & 0.007 \\
\hline & Difference in Facility $(\mathrm{A} / \mathrm{C})$ & 0.99 & $0.90-1.09$ & 0.89 \\
\hline \multicolumn{5}{|l|}{ Site B vs Site $C$} \\
\hline & Intervention $^{\dagger}$ & 1.01 & $0.89-1.15$ & 0.90 \\
\hline & Period & 1.15 & $1.04-1.27$ & 0.007 \\
\hline & Difference in Facility $(\mathrm{B} / \mathrm{C})$ & 1.33 & $1.23-1.44$ & $<0.001$ \\
\hline \multicolumn{5}{|c|}{$\begin{array}{l}\text { Site A, Himeji Primary Emergency Medical Center for Nights and Holidays; Site B, Kobe Children's Primary Emergency Medical Center; Site C, Hanshi } \\
\text { Kita Children's First-Aid Center; OR, odds ratio; Cl, confidence interval }\end{array}$} \\
\hline \multicolumn{5}{|c|}{${ }^{*}$ Threshold of statistical significance was Bonferroni corrected. Two-tailed P values below .0167 were considered statistically significant. } \\
\hline \multicolumn{5}{|c|}{${ }^{\dagger}$ Poster nudge-based antimicrobial stewardship } \\
\hline \multicolumn{5}{|c|}{ ‡ Pre-intervention period and post-intervention period } \\
\hline \multicolumn{5}{|c|}{$\S \mathrm{A} / \mathrm{B}$ shows the ratio of $\mathrm{A}$ to $\mathrm{B}$. } \\
\hline "Facility-specific guideline & & & & \\
\hline
\end{tabular}

Figure 3 shows monthly trends in the all antibiotic prescription rate. The rates at Sites A, B, and C decreased from $11.2 \%, 9.0 \%$, and $10.5 \%$ in 2016 to $5.3 \%$, $5.0 \%$, and $5.2 \%$ in 2019 , respectively. Site B had a significantly smaller reduction than Site A (OR 1.13[95\% Cl 1.04-1.24]; P $=0.004)$. There was no significant difference between Site A and Site C (OR 0.94 [95\%Cl 0.86-1.03]; P= 0.17) and between Site B and Site C (OR 1.07 [95\%Cl 0.99-1.16; P = 0.10]) (Table 4). 
Table 4

All antibiotics prescription rate

\begin{tabular}{|c|c|c|c|c|}
\hline & Variable & OR & $95 \% \mathrm{Cl}$ & P value* \\
\hline \multicolumn{5}{|l|}{ Site A vs Site B } \\
\hline & Intervention $^{\dagger}$ & 1.13 & $1.04-1.24$ & 0.004 \\
\hline & Period $^{\ddagger}$ & 0.60 & $0.56-0.64$ & $<0.001$ \\
\hline & Difference in Facility§ (A/B) & 1.19 & $1.14-1.24$ & $<0.001$ \\
\hline \multicolumn{5}{|l|}{ Site A vs Site C } \\
\hline & Intervention" & 0.94 & $0.86-1.03$ & 0.17 \\
\hline & Period & 0.64 & $0.60-0.67$ & $<0.001$ \\
\hline & Difference in Facility $(\mathrm{A} / \mathrm{C})$ & 1.05 & $1.01-1.10$ & 0.018 \\
\hline \multicolumn{5}{|l|}{ Site B vs Site C } \\
\hline & Intervention $^{\dagger}$ & 1.07 & $0.99-1.16$ & 0.10 \\
\hline & Period & 0.64 & $0.60-0.67$ & $<0.001$ \\
\hline & Difference in Facility $(\mathrm{B} / \mathrm{C})$ & 0.88 & $0.85-0.92$ & $<0.001$ \\
\hline \multicolumn{5}{|c|}{$\begin{array}{l}\text { Site A, Himeji Primary Emergency Medical Center for Nights and Holidays; Site B, Kobe Children's Primary Emergency Medical Center; Site C, Hanshir } \\
\text { Kita Children's First-Aid Center; OR, odds ratio; Cl, confidence interval }\end{array}$} \\
\hline \multicolumn{5}{|c|}{ * Threshold of statistical significance was Bonferroni corrected. Two-tailed P values below .0167 were considered statistically significant. } \\
\hline \multicolumn{5}{|c|}{${ }^{\dagger}$ Poster nudge-based antimicrobial stewardship } \\
\hline \multicolumn{5}{|c|}{ ‡ Pre-intervention period and post-intervention period } \\
\hline \multicolumn{5}{|c|}{$\S \mathrm{A} / \mathrm{B}$ shows the ratio of $\mathrm{A}$ to $\mathrm{B}$. } \\
\hline " Facility-specific guideline & & & & \\
\hline
\end{tabular}

\section{Discussion}

In this study, we compared the effects of facility-specific guideline with the effects of nudge-based ASP for decreasing oral 3GCs prescription at Japanese pediatric PECs using the difference-in-difference method. While the 3GC prescription rate decreased at all sites from 2016 to 2019 , facility-specific guideline was less effective than nudge-based antimicrobial stewardship program and was equivalent to the negative control.

Regarding ASP strategies in the outpatient setting, previous reviews $[2,16,17]$ have stated that antimicrobial use could be improved by several factors, including clinical practice guidelines [18], restrictive policies [19], financial incentives [20], provider feedback [21], patient education [22], communication training [23], and diagnostic stewardship [24]. In particular, the facility-specific guideline was recommended not only for inpatient ASPs [25] but also for outpatient ASP, as it has been reported to be effective in emergency departments and local outpatient settings [9, 26, 27]. If the facility-specific guideline was as effective as nudge-based ASP in Japanese PECs, we would have deemed it a more preferable outpatient ASP strategy because it would not require frequent repeated effort once published. However, the effect of facility-specific guideline on 3GC prescription was less than the effect of nudge-based ASP [14]. We believe there were three reasons for this. First, because the facility-specific guideline did not provide specific feedback to physicians on their prescribing behaviors directly, it was difficult for many physicians who work as part-time employees to understand why certain antimicrobials were recommended or why their own prescribing was inappropriate. A previous report described that multidisciplinary guidelines did not sufficiently change trends in drug prescription, including antibiotics, among 53 general practitioners [28]. The reported reasons were that the general practitioners were not actively involved in the development of the guidelines, and they did not receive immediate and direct feedback about their prescription behaviors. Second, enforcing guidelines describing what physicians should adhere to may lead to resistance and render changing prescribing practices difficult [29]. Previous studies reported that the physician's preference for certain antibiotics [29], fear of infectious complications [30], patient or parent satisfaction [30], influence of pharmaceutical marketing and promotion [31, 32], and differences in cost [31] led to low concordance of guidelines at outpatient settings. Nudge-based antimicrobial stewardship had a positive message based on behavioral psychology through feedback related to the prescribing trends and goals of the entire facility [14]. Therefore, the difference was believed to have been caused by the different psychological effects on the physicians. For the facilityspecific guideline to be more effective in pediatric PECs, it may be necessary to allow many physicians to actively participate in guideline development to ensure more frequent use by part-time employees. Third, the facility-specific guideline based on the national guidelines [15] may not have had a greater effect. We hypothesized that this was because the national guidelines, rather than the facility-specific guideline, accelerated the appropriate use of antimicrobials by physicians who were originally interested in AMR. Furthermore, the facility-specific guideline had no further impact, and physicians who were not interested in AMR might not refer to this guideline. As an effect of national ASPs available in all facilities via website, the $3 \mathrm{GC}$ prescription rate and 
the percentage among all antibiotics decreased at all facilities gradually, including the negative control. However, the facility-specific guideline did not have the effect of further sustaining the decline, as observed in the nudge-based ASP.

The effect of nudge-based ASP showed a significantly smaller reduction in all antibiotic prescription rates than the facility-specific guideline. Although the all antibiotic prescription rate declined at the three facilities, it eventually stabilized at approximately $5.0 \%$. The decrease in the all antibiotic prescription rate was observed in children aged under 15 years in Japan [33], which may be due to the national ASP (this includes formulation of action plans [34, 35] or issuance of a national guidelines [15]) in Japan. Our research model assumed that the effects of ASPs conducted by each facility were constant; however, it was suggested that the effect gradually weakened, and the prescription rate was maintained at constant values. Therefore, we hypothesized that Site B showed a relatively smaller degree of reduction because it had the lowest all antibiotic prescription rate in the pre-intervention period.

Our study has several limitations. First, the results cannot be generalized widely because this was a comparison among facilities in a single region. In the future, we aim to evaluate the possibility of making the results more generalizable by comparing pediatric PECs in different regions of Japan through system automation of data collection and collaborations with local governments. Second, the appropriateness of prescriptions could not be evaluated because the diagnoses of patients who were prescribed antibiotics were not surveyed, while the characteristics and diagnoses of all patients visiting each facility were surveyed. We plan to investigate all prescribed antimicrobials for each disease and compare changes in the reduction of inappropriate antimicrobial prescriptions, such as $3 \mathrm{GCs}$ and macrolides prescribed for the common cold and acute upper respiratory tract infections, in all these centers. Third, one or two physicians worked at several facilities. However, they were only a few physicians of the dozens working at each facility. Thus, we considered there would be only a small impact. Fourth, this study was conducted until December 2019, and trends in prescribing after January 2020 were not examined. However, since January 2020, the coronavirus disease 2019 pandemic has had a significant impact on trends in Japan regarding emergency department visits and antimicrobial prescriptions due to school closures and avoidance of accessing hospitals [36, 37]. Therefore, we considered that investigating prescribing trends until December 2019, when the trends were not affected by the coronavirus disease 2019 pandemic, was sufficiently suitable to assess the effects of the interventions.

\section{Conclusion}

Although facility-specific guideline development was simple, economical, and required fewer efforts, the effect was observed to be less than the effect of nudge-based ASP for decreasing use of 3GCs in Japanese pediatric PECs and was no different from that of the negative control. To promote the decrease of 3GCs usage in Japanese pediatric PECs beyond the national ASP, the introduction of facility-specific guideline was not sufficient; therefore, we believe that nudge-based ASP should be the main focus.

\section{List Of Abbreviations}

$3 \mathrm{GC}$ - third-generation cephalosporin

AMR - antimicrobial resistance

ASP - antimicrobial stewardship program

$\mathrm{Cl}$ - confidence interval

$\mathrm{OR}$ - odds ratio

PEC - primary emergency care center

\section{Declarations}

Acknowledgments: We have no acknowledgments of people, grants, or funds.

Funding: Not applicable.

Conflict of interest/Competing interests: The authors declare that they have no conflict of interest.

Availability of data and material: The data that support the findings of this study are openly available.

Code availability: Not applicable.

Authors' Contributions: Ishida and Kasai conceptualized and designed the study. Otake, Kusama, Myojin, Kimura, Kamiyoshi, and Takumi designed the data collection, collected data, and carried out the initial analyses. Tsuzuki carried out statistical analysis. Otake, Kusama, and Tsuzuki drafted the initial manuscript. Myojin, Kimura, Kamiyoshi, Takumi, Ishida, and Kasai critical reviewed and revised the manuscript for important intellectual content. All authors confirmed final approval of the version to be published and agreement to be accountable for all aspects of the work in ensuring that questions related to the accuracy or integrity of any part of the work are appropriately investigated and resolved.

Ethics approval: this study was approved by the institutional ethics committees of Kobe Children's Hospital (Approval Number 2020-61), Japanese Red Cross Society Himeji Hospital (Approval Number 2020-39), and Kobe Children's Primary Emergency Medical Center (Approval Number 1). 
Consent to participate: We obtained opt-out consent from the patients' parents.

Consent for publication: We obtained opt-out consent from the patients' parents.

\section{References}

1. World Health Organization Global action plan on antimicrobial resistance.

https://apps.who.int/iris/bitstream/handle/10665/193736/9789241509763_eng.pdf?sequence=1. Accessed 6 Febr 2022

2. Gerber JS, Jackson MA, Tamma PD et al (2021) Antibiotic stewardship in pediatrics. Pediatr 147. https://doi.org/10.1542/peds.2020-040295

3. Wendt JM, Cohen JA, Mu Y et al (2014) Clostridium difficile infection among children across diverse us geographic locations. Pediatrics 133:651-658. https://doi.org/10.1542/peds.2013-3049

4. Palms DL, Hicks LA, Bartoces M et al (2018) Comparison of antibiotic prescribing in retail clinics, urgent care centers, emergency departments, and traditional ambulatory care settings in the United States. JAMA Intern Med 178:1267-1269. https://doi.org/10.1001/jamainternmed.2018.1632

5. Centers for Disease Control and Prevention (2021) Antibiotic use in the United States. Update Prog Oppor. https://www.cdc.gov/antibioticuse/pdfs/stewardship-report-2021-H.pdf. Accessed 6 Febr 2022

6. Hayes R, Merritt B, Lewis S et al (2019) Antibiotic prescriptions for upper respiratory infections in a pediatric office versus an urgent Care Center. Glob Pediatr Heal 6:X1983563. https://doi.org/10.1177/2333794X19835632

7. Incze MA, Redberg RF, Katz MH (2018) Overprescription in urgent care clinics-The fast and the spurious. JAMA Intern Med 178:1269-1270. https://doi.org/10.1001/jamainternmed.2018.1628

8. Islam S, Mannix MK, Breuer RK, Hassinger AB (2020) Guideline adherence and antibiotic utilization by community pediatricians, private urgent care centers, and a pediatric emergency department. Clin Pediatr (Phila) 59:21-30. https://doi.org/10.1177/0009922819879462

9. Sanchez GV, Fleming-Dutra KE, Roberts RM, Hicks LA (2016) Core elements of outpatient antibiotic stewardship. MMWR Recomm Rep 65:1-12. https://doi.org/10.15585/mmwr.rr6506a1

10. Muraki Y, Yagi T, Tsuji Y et al (2016) Japanese antimicrobial consumption surveillance: First report on oral and parenteral antimicrobial consumption in Japan (2009-2013). J Glob Antimicrob Resist 7:19-23. https://doi.org/10.1016/j.jgar.2016.07.002

11. Kinoshita N, Morisaki N, Uda K et al (2019) Nationwide study of outpatient oral antimicrobial utilization patterns for children in Japan (2013-2016). J Infect Chemother 25:22-27. https://doi.org/10.1016/j.jiac.2018.10.002

12. Uda K, Okubo Y, Kinoshita N et al (2019) Nationwide survey of indications for oral antimicrobial prescription for pediatric patients from 2013 to 2016 in Japan. J Infect Chemother 25:758-763. https://doi.org/10.1016/j.jiac.2019.03.004

13. Hsia Y, Sharland M, Jackson C et al (2019) Consumption of oral antibiotic formulations for young children according to the WHO Access, Watch, Reserve (AWaRe) antibiotic groups: An analysis of sales data from 70 middle-income and high-income countries. Lancet Infect Dis 19:67-75. https://doi.org/10.1016/S1473-3099(18)30547-4

14. Shishido A, Otake S, Kimura M et al (2021) Effects of a nudge-based antimicrobial stewardship program in a pediatric primary emergency medical center. Eur J Pediatr 135:33-39. https://doi.org/10.1007/s00431-021-03979-3

15. Tuberculosis and Infectious Diseases Control Division, Health Service Bureau, Ministry of Health Labour and Welfare Manual of antimicrobial stewardship. The 1st Edition (Written in Japanese). http://www.mhlw.go.jp/file/06-Seisakujouhou-10900000-Kenkoukyoku/0000166612.pdf. Accessed 6 Febr 2022

16. Drekonja DM, Filice GA, Greer N et al (2015) Antimicrobial stewardship in outpatient settings: A systematic review. Infect Control Hosp Epidemiol 36:142-152. https://doi.org/10.1017/ice.2014.41

17. Avent ML, Cosgrove SE, Price-Haywood EG, Van Driel ML (2020) Antimicrobial stewardship in the primary care setting: From dream to reality? BMC Fam Pract 21:134. https://doi.org/10.1186/s12875-020-01191-0

18. Venekamp RP, Rovers MM, Verheij TJM et al (2012) Treatment of acute rhinosinusitis: Discrepancy between guideline recommendations and clinical practice. Fam Pract 29:706-712. https://doi.org/10.1093/fampra/cms022

19. Marshall D, Gough J, Grootendorst $P$ et al (2006) Impact of administrative restrictions on antibiotic use and expenditure in Ontario: Time series analysis. J Health Serv Res Policy 11:13-20. https://doi.org/10.1258/135581906775094253

20. Martens JD, Werkhoven MJ, Severens JL, Winkens RAG (2007) Effects of a behaviour independent financial incentive on prescribing behaviour of general practitioners. J Eval Clin Pract 13:369-373. https://doi.org/10.1111/j.1365-2753.2006.00707.x

21. Madridejos-Mora R, Amado-Guirado E, Pérez-Rodríguez MT (2004) Effectiveness of the combination of feedback and educational recommendations for improving drug prescription in general practice. Med Care 42:643-648. https://doi.org/10.1097/01.mlr.0000129495.43422.58

22. Steinman MA, Ranji SR, Shojania KG, Gonzales R (2006) Improving antibiotic selection: A systematic review and quantitative analysis of quality improvement strategies. Med Care 44:617-628. https://doi.org/10.1097/01.mlr.0000215846.25591.22

23. Mangione-Smith R, Zhou C, Robinson JD et al (2015) Communication practices and antibiotic use for acute respiratory tract infections in children. Ann Fam Med 13:221-227. https://doi.org/10.1370/afm.1785

24. Gerber JS, Prasad PA, Russell Localio A et al (2015) Variation in antibiotic prescribing across a pediatric primary care network. J Pediatr Infect Dis Soc 4:297-304. https://doi.org/10.1093/jpids/piu086

Page $9 / 12$ 
25. Barlam TF, Cosgrove SE, Abbo LM et al (2016) Implementing an Antibiotic Stewardship Program: Guidelines by the Infectious Diseases Society of America and the Society for Healthcare Epidemiology of America. Clin Infect Dis 62:e51-e77. https://doi.org/10.1093/cid/ciw118

26. Slekovec C, Leroy J, Vernaz-Hegi N et al (2012) Impact of a region wide antimicrobial stewardship guideline on urinary tract infection prescription patterns. Int J Clin Pharm 34:325-329. https://doi.org/10.1007/s11096-012-9606-6

27. Timbrook TT, Caffrey AR, Ovalle A et al (2017) Assessments of opportunities to improve antibiotic prescribing in an emergency department: A period prevalence survey. Infect Dis Ther 6:497-505. https://doi.org/10.1007/s40121-017-0175-9

28. Martens JD, Winkens RAG, Van Der Weijden T et al (2006) Does a joint development and dissemination of multidisciplinary guidelines improve prescribing behaviour: A pre/post study with concurrent control group and a randomised trial. BMC Health Serv Res 6:145.

https://doi.org/10.1186/1472-6963-6-145

29. Grigoryan L, Zoorob R, Wang H, Trautner BW (2015) Low concordance with guidelines for treatment of acute cystitis in primary care. Open Forum Infect Dis 2:ofv159. https://doi.org/10.1093/ofid/ofv159

30. Sanchez GV, Roberts RM, Albert AP et al (2014) Effects of knowledge, attitudes, and practices of primary care providers on antibiotic selection, United States. Emerg Infect Dis 20:2041-2047. https://doi.org/10.3201/eid2012.140331

31. Taur Y, Smith MA (2007) Adherence to the Infectious Diseases Society of America guidelines in the treatment of uncomplicated urinary tract infection. Clin Infect Dis 44:769-774. https://doi.org/10.1086/511866

32. Ono A, Ishikane M, Kusama Y et al (2020) The first national survey of antimicrobial use among dentists in Japan from 2015 to 2017 based on the national database of health insurance claims and specific health checkups of Japan. PLoS ONE 15:e0244521.

https://doi.org/10.1371/journal.pone.0244521

33. AMR Clinical Reference Center (2022) Surveillance of antibiotic use by prefecture and age category, based on data from the NDB. http:// http://amrcrc.ncgm.go.jp/surveillance/010/Eng/3_AMU_by_age_category.pdf. Accessed Feb 6,

34. The Government of Japan. National Action Plan on Antimicrobial Resistance (AMR) 2016-2020. https://www.mhlw.go.jp/file/06-Seisakujouhou10900000-Kenkoukyoku/0000138942.pdf. Accessed 6 Febr 2022

35. Kusama Y, Tsuzuki S, Muraki Y et al (2021) The effects of Japan's National Action Plan on antimicrobial Resistance on antimicrobial use. Int J Infect Dis 103:154-156. https://doi.org/10.1016/j.jid.2020.11.158

36. Iwata K, Doi A, Miyakoshi C (2020) Was school closure effective in mitigating coronavirus disease 2019 (COVID-19)? Time series analysis using Bayesian inference. Int J Infect Dis 99:57-61. https://doi.org/10.1016/j.jijid.2020.07.052

37. Kishimoto K, Bun S, Shin J et al (2021) Early impact of school closure and social distancing for COVID-19 on the number of inpatients with childhood non-COVID-19 acute infections in Japan. Eur J Pediatr 180:2871-2878. https://doi.org/10.1007/s00431-021-04043-w

\section{Figures}

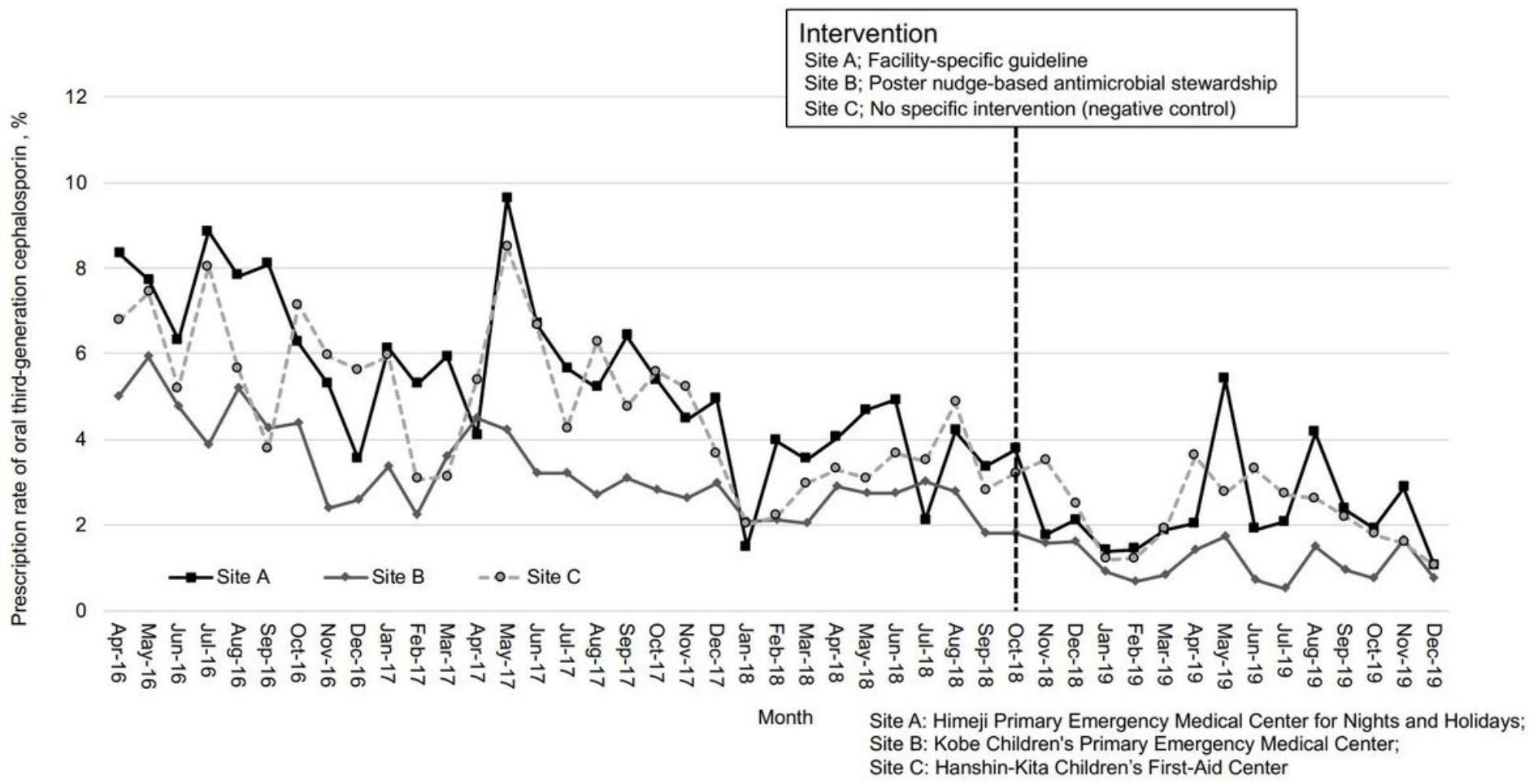

Fig. 1 
Figure 1

Trends in oral third-generation cephalosporins prescription rate. The rate at Sites A, B, and C decreased from $6.7 \%, 4.2 \%$, and $6.1 \%$ in 2016 to $2.3 \%, 1.0 \%$, and $2.0 \%$ in 2019 , respectively. Site B had a greater reduction than Site A and Site C. There was no significant difference between Site A and Site C.

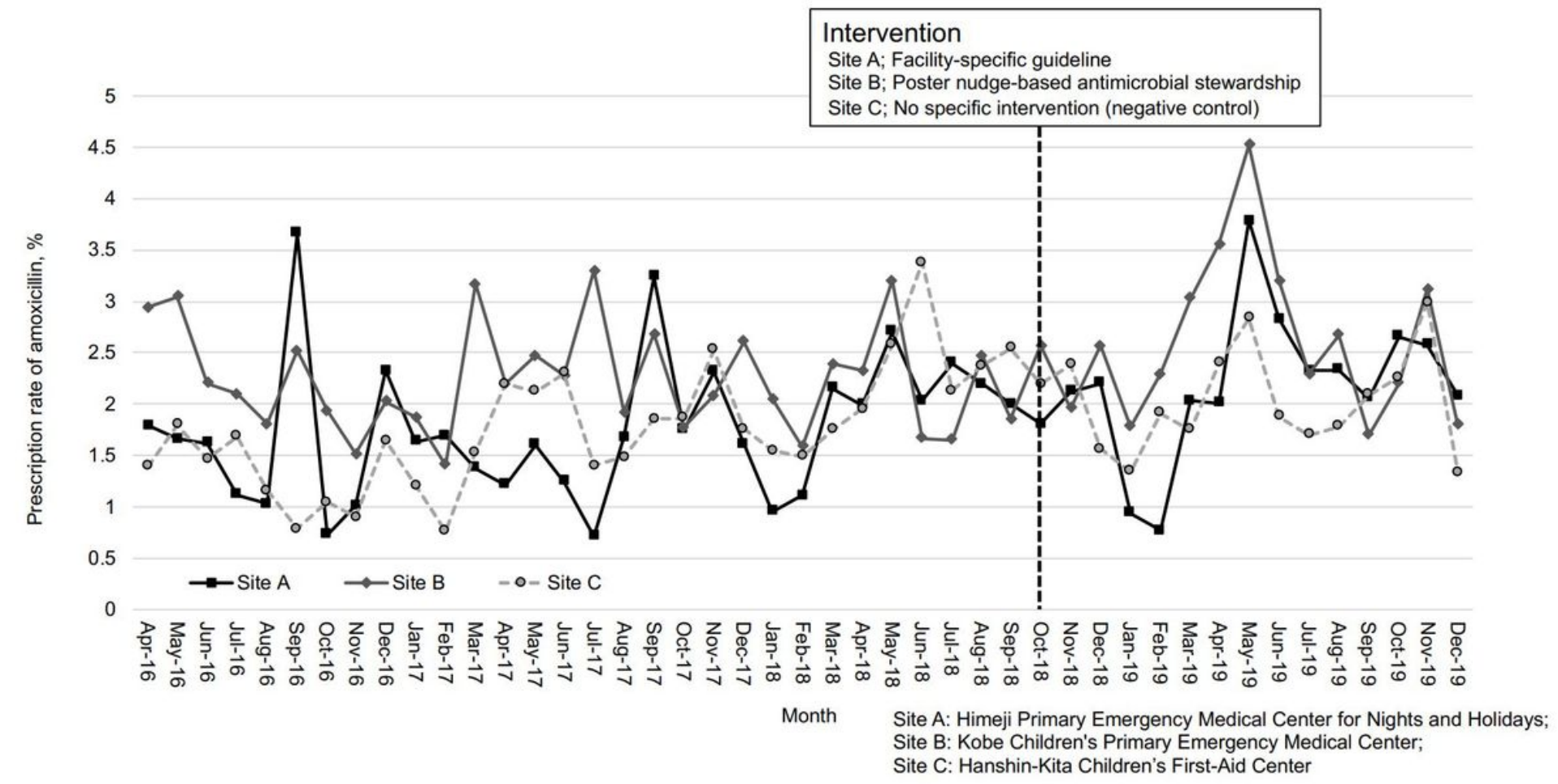

Fig. 2

\section{Figure 2}

Trends in the amoxicillin prescription rate. The rate at Sites A, B, and C increased from $1.6 \%, 2.2 \%$, and $1.3 \%$ in 2016 to $2.0 \%, 2.6 \%$, and $1.9 \%$ in 2019 , respectively. There was no significant difference among any of the centers. 


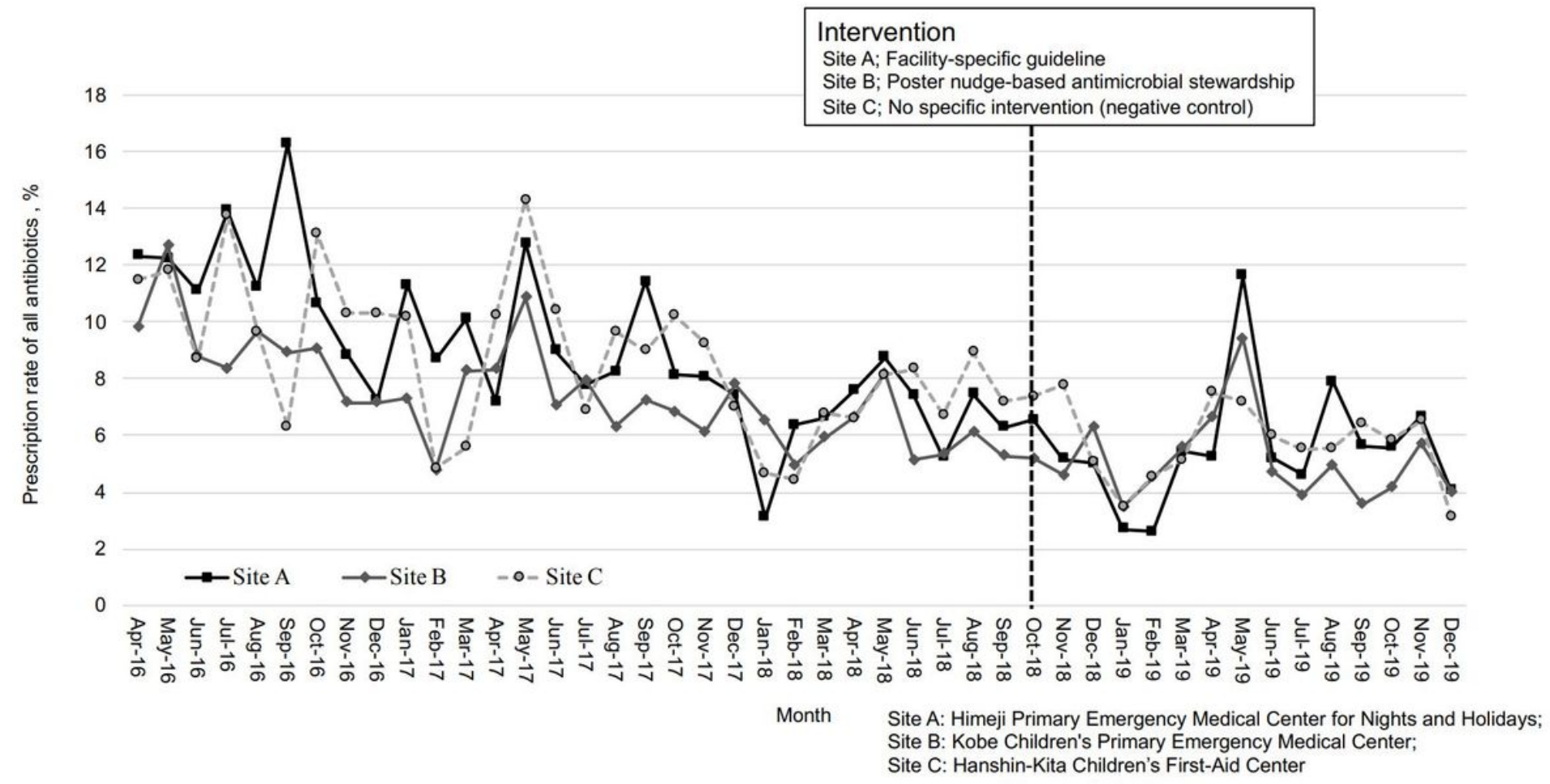

Fig. 3

Figure 3

Trends in all antibiotics prescription rate. The rate at Sites A, B, and C decreased from $11.2 \%, 9.0 \%$, and $10.5 \%$ in 2016 to $5.3 \%, 5.0 \%$, and $5.2 \%$ in 2019 . Site A had a smaller reduction than Site B. There was no significant difference between Site A and Site C and between Site B and Site C. 